Int. J. Electrochem. Sci., 13 (2018) $1321-1330$

\title{
Nano-Magnetic Hydrotalcite Synthesized by Double In-situ Hydrothermal Method with Enhanced Electromagnetic Characteristics
}

\author{
Li Honglin ${ }^{1,2, *}$, Ammar Bin Yousaf ${ }^{3}$, Akif Zeb $^{4}$, Peter Kasak ${ }^{3}$, Syed Javaid Zaidi ${ }^{3}$, Li Ying ${ }^{1}$, \\ Luo Weiqing ${ }^{1}$, Liu Shuaishuai ${ }^{1}$, Han Tianli ${ }^{1}$, Li Mingling ${ }^{1,2}$ \\ ${ }^{1}$ College of Chemistry and Material Engineering, Chao Hu University, Hefei 238000, China \\ ${ }^{2}$ Institute of Novel Functional Materials and Fine Chemicals, Chao Hu University, Hefei 238000, \\ China \\ ${ }^{3}$ Center for Advanced Materials, Qatar University, Doha 2713, Qatar \\ ${ }^{4}$ Institute of Environmental Sciences and Engineering (IESE), School of Civil and Environmental \\ Engineering (SCEE), National University of Sciences and Technology (NUST), Sector H-12, \\ Islamabad, Pakistan \\ *E-mail: $\underline{\text { hlin777@163.com }}$
}

doi: $10.20964 / 2018.02 .41$

Received: 11 August 2017 / Accepted: 17 September 2017 / Published: 28 December 2017

\begin{abstract}
A series of nano-magnetic hydrotalcite with different content of $\mathrm{CoFe}_{2} \mathrm{O}_{4}$ is prepared by homogeneous double in-situ hydrothermal method using self-synthesised $\mathrm{CoFe}_{2} \mathrm{O}_{4}$, Cobalt nitrate hexahydrate $\left(\mathrm{Co}\left(\mathrm{NO}_{3}\right)_{2} \cdot 6 \mathrm{H}_{2} \mathrm{O}\right)$, magnesium nitrate hexahydrate $\left(\mathrm{Mg}\left(\mathrm{NO}_{3}\right)_{2} \cdot 6 \mathrm{H}_{2} \mathrm{O}\right)$, nitrate aluminum nonahydrate $\left(\mathrm{Al}\left(\mathrm{NO}_{3}\right)_{3} \cdot 9 \mathrm{H}_{2} \mathrm{O}\right)$, and sodium hydroxide $(\mathrm{NaOH})$ as starting materials. The crystal structure, morphology, magnetic and thermal stability of the samples were characterized in detail by X-ray diffraction (XRD), scanning electron microscope (SEM), vibrating sample magnetometer (VSM) and thermal gravimetric differential thermal analyzer (TG-DTA) techniques. XRD patterns showed that a small amount of $\mathrm{CoFe}_{2} \mathrm{O}_{4}$ did not affect the crystallization properties of hydrotalcite, and magnetic hydrotalcite has typical characteristic peak containing both hydrotalcite and $\mathrm{CoFe}_{2} \mathrm{O}_{4}$. SEM images indicated the magnetic hydrotalcite samples were lamellar with magnetic matrix of $\mathrm{CoFe}_{2} \mathrm{O}_{4}$ adsorbed on the surface of LDHs layer. The results of VSM displayed that the magnetic hydrotalcite was ferromagnetic, and sample saturation magnetization of three samples increased with the increasing $\mathrm{CoFe}_{2} \mathrm{O}_{4}$ content with the values of $1.35,2.7$ and $5.9 \mathrm{eum} / \mathrm{g}$. TG-DTA results indicated the thermal decomposition characteristics of magnetic hydrotalcite is similar to the characteristics of pure hydrotalcite thermal decomposition and the addition of magnetic matrix improved the thermal decomposition temperature of the hydrotalcite.
\end{abstract}

Keywords: hydrothermal;double in-situ;Magnetic; hydrotalcite; structure; properties 


\section{FULL TEXT}

(C) 2018 The Authors. Published by ESG (www.electrochemsci.org). This article is an open access article distributed under the terms and conditions of the Creative Commons Attribution license (http://creativecommons.org/licenses/by/4.0/). 